\title{
REAKSI HARGA SAHAM PERUSAHAAN AGRIBISNIS INDEKS LQ-45 TERHADAP PERUBAHAN VARIABEL MAKROEKONOMI
}

\author{
Alghif Aruni Nur Rukman ${ }^{1}$, Harianto ${ }^{2}$ dan Suprehatin ${ }^{3}$ \\ 1)Mahasiswa Program Magister Sains Agribisnis, Sekolah Pascasarjana, Institut Pertanian Bogor \\ 2,3)Departemen Agribisnis, Fakultas Ekonomi dan Manajemen, Institut Pertanian Bogor \\ e-mail: 1)alghifanr@gmail.com
}

(Diterima 29 Mei 2019/Disetujui 19 Juni 2019)

\begin{abstract}
This study aims to analyze the effect of changes in macroeconomic variables, namely exchange rates, interest rates, and inflation on stock prices of agribusiness companies on the LQ-45 index. This study used monthly time series data from 2008-2018 and analyzed by the VECM method. The results showed that the stock price reaction of eight agribusiness companies in the LQ-45 index varies with changes in macroeconomic variables both in the short and long term. In the short term, changes in exchange rates had a positive and significant effect on one company stock prices, while changes in inflation and interest rates had a negative and significant effect on four companies and one company respectively. In the long term, the results showed that changes in exchange rates had a positive and significant effect on two companies' stock prices, while it had a negative and significant effect on five companies. The result also showed that changes in inflation had a positive and negative effect on one company and six companies respectively in the long term. Also besides changes in interest rates had a positive and negative effect on two companies' stock prices respectively.
\end{abstract}

Keywords: macroeconomic variables, stock price, vector error correction model

\begin{abstract}
ABSTRAK
Penelitian ini bertujuan untuk menganalisis pengaruh perubahan variabel makroekonomi yaitu nilai tukar, suku bunga dan inflasi terhadap harga saham perusahaan agribisnis pada indeks LQ-45. Studi ini menggunakan data bulanan time series tahun 2008-2018 dan dianalisis dengan metode VECM. Hasil penelitian menunjukkan bahwa reaksi harga saham perusahaan agribisnis pada indeks LQ-45 berbeda-beda terhadap perubahan variabel makroekonomi baik pada jangka pendek maupun jangka panjang. Pada jangka pendek, terdapat satu harga saham perusahaan yang secara signifikan bereaksi positif terhadap perubahan nilai tukar, kemudian pada perubahan inflasi didapatkan empat harga saham perusahaan yang secara signifikan berpengaruh negatif dan perubahan suku bunga menyebabkan satu perusahaan yang secara signifikan berpengaruh negatif. Pada jangka panjang, hasil penelitian didapatkan dua harga saham perusahaan bereaksi positif terhadap perubahan nilai tukar dan lima harga saham perusahaan yang secara signifikan bereaksi negatif, kemudian pada perubahan inflasi didapatkan satu perusahaan yang secara signifikan bereaksi positif dan enam harga saham perusahaan yang bereaksi negatif. Pada perubahan suku bunga menyebabkan dua harga saham perusahaan yang secara signifikan bereaksi positif dan dua harga saham perusahaan yang bereaksi negatif.
\end{abstract}

Kata Kunci : variabel makroeokonomi, harga saham, Vector error correction model

\section{PENDAHULUAN}

Sektor pertanian merupakan salah satu sektor penting bagi perekonomian Indonesia yang berkontribusi pada pendapatan domestik bruto (PDB), tenaga kerja dan devisa negara. Pada tahun 2017, sektor pertanian berkontribusi pada PDB Indonesia sebesar 13,14 persen, nilai tersebut merupakan terbesar kedua setelah sektor industri (BPS 2018). Para pelaku yang berkontribusi dalam sektor pertanian dilakukan dengan berbagai profesi yaitu sebagai petani, pekerja dan pebisnis baik skala kecil maupun skala besar. Distribusi tenaga kerja sektor pertanian sebesar 35,09 
persen dan jumlah perusahaan-perusahaan yang berbadan hukum yang bergerak di sektor pertanian juga jumlahnya mengalami peningkatan yaitu sebesar 19,01 persen dari tahun 2003 (Sensus Pertanian 2014). Potensi tersebut perlu dikelola dengan baik karena kita mengetahui bahwa untuk menjadi negara maju membutuhkan jumlah pelaku yang berprofesi sebagai wirausaha (entrepreneur), laporan Global Entrepreuneurship Index (2018) menyatakan bahwa Indonesia berada pada peringkat 94 dari 137 negara, masih tertinggal dari negara maju.

Salah satu sumber dalam meningkatkan kinerja seorang entrepreneur adalah sumber pembiayaan di mana para entrepreneur perlu bekerja keras untuk mendapatkan sumber tersebut dalam menjalankan usahanya agar dapat bertahan ditengah persaingan bisnis yang semakin tinggi. Kendala ini sebenarnya sudah sejak lama diberikan solusi oleh pemerintah melalui pasar modal, di mana sarana ini dapat menghubungkan investor dan perusahaan. Pasar modal di Indonesia dikenal dengan Bursa Efek Indonesia (BEI).

Tabel 1. Perkembangan Jumlah Emiten

\begin{tabular}{|c|c|c|c|}
\hline \multirow{2}{*}{\multicolumn{2}{|c|}{$\begin{array}{l}\text { Akhir Periode } \\
\text { Tahun Jumlah } \\
\text { Emiten }\end{array}$}} & \multicolumn{2}{|c|}{ Perdagangan Saham } \\
\hline & & $\begin{array}{l}\text { Volume } \\
\text { (miliar) }\end{array}$ & $\begin{array}{l}\text { Nilai }\left(R_{p}\right. \\
\text { Triliun) }\end{array}$ \\
\hline 2011 & 440 & $1.203,55$ & $1.223,44$ \\
\hline 2012 & 459 & $1.053,76$ & $1.116,11$ \\
\hline 2013 & 483 & $1.342,66$ & $1.522,12$ \\
\hline 2014 & 506 & $1.327,02$ & $1.453,39$ \\
\hline 2015 & 521 & $1.446,31$ & $1.406,36$ \\
\hline 2016 & 537 & $1.925,42$ & $1.844,59$ \\
\hline
\end{tabular}

Sumber : BEI, 2018

BEI mengalami berbagai perkembangan selama aktifitasnya, khususnya dalam peningkatan pertumbuhan emiten (saham perusahaan yang terdaftar dilantai bursa). Saham-saham emiten tersebut diperdagangkan setiap harinya di lantai Bursa saham. Peningkatan jumlah emiten tersebut dapat disebabkan karena BEI menyediakan fasilitas untuk memindahkan dana dari pihak yang mempunyai kelebihan dana (investor) kepada pihak yang membutuhkan dana (emiten). Kegiatan tersebut menjadikan adanya proses saling berharap untuk dapat menerima imbalan return untuk masing-masing pihak. Perkembangan emiten di BEI (Tabel 1).

Investasi saham memiliki peluang dan bersifat penting bagi masyarakat Indonesia, karena menurut laporan PT Kustodian Sentral Efek Indonesia dalam siaran pressnya menyatakan komposisi kepemilikan saham asing lebih mendominasi daripada lokal yaitu 53 persen dan 47 persen. Hal tersebut berpotensi buruk terhadap perkonomian Indonesia dimasa depan karena jika kondisi ekonomi global tidak baik, sewaktu-waktu uang beredar yang dimiliki asing akan kembali kepada negara asalnya dan tentu akan berdampak pada kondisi ekonomi Indonesia. Kondisi tersebut perlu diwasapadai melalui peningkatan jumlah kepemilikan saham lokal.

Agribisnis merupakan salah satu indeks sektoral yang dibentuk oleh BEI untuk memudahkan para investor yang berminat menanamkan sahamnya di sektor pertanian. Perusahaan tersebut dikategorikan berdasarkan pengertian pertanian dalam arti luas, yaitu perusahaan yang bergerak di bidang perkebunan, perikanan, peternakan maupun pangan. Perusahaan-perusahaan agribisnis telah berkontribusi dalam menciptakan peluang bagi para investor untuk mendapatkan return, dalam laporan terbarunya total jumlah perusahaan agribisnis yang telah menjadi perusahaan go public atau bergabung dengan BEI adalah 30 perusahaan (OJK 2017) di mana dari perusahan-perusahaan tersebut terdapat beberapa perusahaan yang tercatat sebagai perusahaan indeks LQ-45.

Indeks LQ-45 merupakan bagian dari cara BEI menyediakan sarana bagi investor untuk lebih mudah dalam melakukan aktivitas perdagangannya. Indeks ini menggunakan 45 emiten yang dipilih berdasarkan pertimbangan likuiditas dan kapitalisasi pasar dengan kriteria-kriteria yang telah ditentukan oleh BEI. Review dan 
pergantian perusahaan dilakukan setiap 6 bulan sekali (IDX 2010).

Tingkat risiko saham pada indeks LQ-45 lebih rendah daripada saham non LQ-45, sebagaimana dilaporkan dalam penelitian oleh Polakitan (2015) bahwa tingkat risiko saham LQ-45 lebih rendah daripada saham non LQ-45, hal tersebut disebabkan karena saham LQ-45 merupakan gabungan dari perusahaan yang memiliki likuiditas yang tinggi sehingga perputarannya lebih cepat daripada saham non LQ-45. Tingkat risiko yang lebih rendah pada saham LQ-45 menjadi pertimbangan dari para investor untuk menanamkan saham pada perusahaan di LQ-45 sehingga besarnya risiko memengaruhi harapan return bagi para investor

Sebagaimana teori dalam bisnis bahwa setiap aktivitas bisnis memiliki potensi ancaman atau risiko yang perlu diwaspadai, dalam hal ini pasar saham tidak bisa dilepaskan dari risiko yang dapat menurunkan kinerja, di mana salah satu faktor yang dapat memengaruhi kinerja dari pasar saham adalah perubahan dari variabel makroekonomi. Pengaruh tersebut diperkuat dengan fakta yang pernah terjadi pada kondisi pasar yang pernah menurun tajam yang disebabkan oleh perubahan variabel makreokonomi pada tahun 2008 atau dikenal dengan krisis keuangan. Indeks saham sektor Agri menjadi salah satu dari indeks sektor lain yang terkena dampak dari krisis tersebut (Gambar 1)

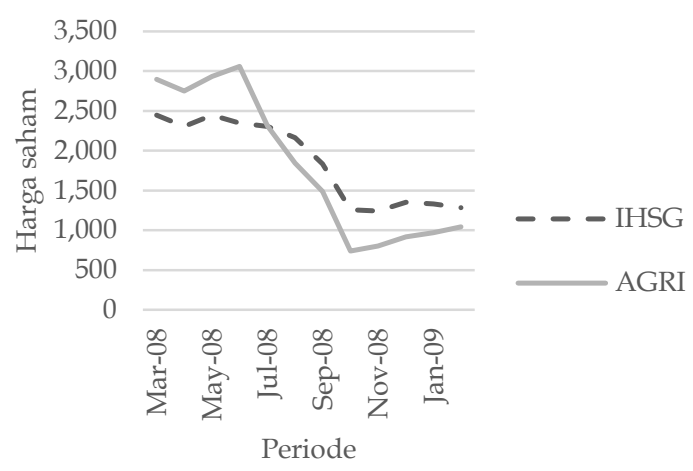

Gambar 1. Dampak krisis pada indeks pertanian (Sumber: BEI, 2018)
Kondisi tersebut menyebabkan peningkatan inflasi disertai dengan peningkatan suku bunga dan pelemahan nilai tukar rupiah terhadap US\$ dollar yang berdampak juga pada pelaku di bursa. Hal tersebut dapat dilihat dari terkoreksinya nilai IHSG yang menurun yang menjadi ukuran dari menarik atau tidaknya suatu investasi. Begitupun juga nilai dari sektor Agri yang mengalami penurunan yang mana kondisi tersebut juga dapat berdampak pada perusahaan-perusahaan yang bergerak di sektor agribisnis. Meskipun Indeks LQ-45 merupakan perusahaan pilihan akan tetapi perusahaan tersebut tidak bisa juga terhindar dari kondisi perubahan variabel makroekonomi, terkhusus juga Indonesia sebagai negara berkembang di mana perkembangannya masih bisa dipengaruhi oleh pergerakan kondisi ekonomi negara maju.

Pentingnya kontribusi perusahaan agribisnis karena pada sektor tersebut teradapat subsektor yang dibutuhkan yaitu seperti subsektor perkebunan, peternakan, perikanan dan pangan yang mana semua subsektor tersebut berhubungan dengan kebutuhan masyarakat Indonesia sehingga perlu diwaspadai jika terjadi perubahan pada variabel yang tidak bisa dikontrol oleh perusahaan itu sendiri yaitu variabel-variabel eksternal perusahaan seperti nilai tukar, Suku bunga dan inflasi karena perubahaan dari variabel tersebut dampaknya akan dirasakan juga oleh masyarakat luas

Ada beberapa studi yang menguji perubahan variabel makroekonomi terhadap harga saham baik secara regional maupun global. Studi regional dilakukan oleh Suselo, dkk (2015) yang menyatakan bahwa nilai tukar dan inflasi berpengaruh negatif terhadap harga saham perusahaan sedangkan suku bunga berpengaruh positif. Kemudian Suyati (2015) menyatakan bahwa nilai tukar, inflasi dan Suku bunga berpengaruh signifikan pada harga saham perusahaan property. Kemudian Prakoso, dkk (2018) yang meneliti return perusahaanperusahaan Indeks LQ-45 menyatakan 
bahwa Suku bunga Bank Indonesia berpengaruh positif sedangkan nilai tukar berpengaruh negatif. Studi mengenai hubungan variabel makroekonomi secara global telah dilakukan oleh Singh et al (2011) yang menyatakan bahwa inflasi dan nilai tukar berpengaruh negatif pada seluruh portofolio perusahaan besar dan menengah di Taiwan, kemudian Kuwornu (2011) menyatakan bahwa inflasi berpengaruh positif sedangkan nilai tukar berpengaruh negatif terhadap return saham di Ghana. Almajali dan AL-assaf (2014) melakukan penelitian pada kinerja pasar saham di Jordan bahwa terdapat hubungan janka panjang terhadap perubahan inflasi.

Metode penelitian serupa yaitu Vector Error Correction Model telah dilakukan oleh Maysami, et al (2000) untuk mengetahui hubungan variabel makroekonomi di pasar modal singapura, kemudian Caporale dan Soliman (2013) melihat analisis impuls response di pasar saham inggris kemudian di Indonesia Prio (2010) yang melihat pengaruh variabel makroekonomi pada indeks perusahaan LQ-45 sedangkan Abu FRA (2011) melihat hubungan jangka panjang harga minyak dunia dan variabel makroekonomi terhadap indeks harga saham (studi komparatif: Asia Tenggara, Asia Timur, Eropa dan Amerika) dan Dirga, dkk (2016) meneliti mengenai hubungan variabel makroekonomi terhadap kelompok saham subsektor perkebunan.

Berdasarkan latar belakang dan perumusan masalah yang telah diuraikan, penelitian ini bertujuan untuk mengetahui bagaimana reaksi harga saham perusahaan agribisnis indeks LQ-45 terhadap perubahan variabel makroekonomi

\section{METODE}

\section{JENIS DAN SUMBER DATA}

Jenis data yang digunakan dalam penelitian ini adalah data sekunder berupa data deret waktu (time series) bulanan dengan periode data dari Januari 2008 hingga Desember 2018. Data tersebut yaitu harga penutupan saham perusahaan, nilai tukar, inflasi dan Suku bunga Bank Indonesia (BI), dimana sumber data yang diperoleh yaitu dari BEI, Yahoo finance, Bank Indonesia, kementrian perdagangan serta referensi lain yang berhubungan dengan perkembangan saham. Harga yang digunakan adalah monthly closing prices dari perusahaan agribisnis yang pernah masuk pada indeks LQ-45 dimana sepanjang periode tersebut didapatkan jumlah perusahaan sebanyak sembilan yaitu UNSP, SGRO, LSIP, TBLA, AALI, CPRO, CPIN, MAIN dan BISI. Masing-masing data menunjukkan pergerakan yang berbeda-beda.

\section{Analisis Data}

Analisis data yang digunakan adalah analisis deskriptif dan kuantitatif. Analisis deskriptif menjelaskan bagaimana pergerakan perubahan variabel dan hubungan di antara masing-masing variabel. Analisis kuantitatif dilakukan dengan pendekatan Vector Error Correction Model (VECM) karena berdasarkan hasil dari analisis menghasilkan data yang tidak stasioner pada tingkat level kemudian data stasioner pada turunan pertama dan memiliki nilai kointegrasi pada masingmasing model persamaan. Model persamaan yang digunakan dalam mendapatkan reaksi harga saham perusahaan terhadap perubahan variabel makroekonomi adalah sebagai berikut,

$$
\begin{aligned}
& L n_{-} H_{\mathrm{t}=\mathrm{a}_{\mathrm{i} 0}}+\sum_{i=1} \underset{i=1}{L n_{-}} K U R S_{t-i}+\Gamma_{i} \sum N F_{t-i}+w_{i} S \mathbb{B} I_{t-i} \\
& +\mathrm{e}_{\mathrm{t}}=1
\end{aligned}
$$

\section{Dimana :}

$L n \_H_{t} \quad$ : logaritma natural harga penutupan saham bulanan perusahaan agribisnis subsektor pangan (BISI), subsektor perkebunan (UNSP, SGRO, LSIP, TBLA, AALI), subsektor perikanan (CPRO), subsektor peternakan (CPIN, MAIN)

$L n_{-} K U R S_{t} \quad$ : logaritma natural nilai tukar $I N F_{t} \quad:$ Inflasi

SBI $\quad$ : Suku bunga BI SBI

a ${ }_{i 0} \quad:$ Konstanta

$\Phi \Gamma \omega \quad$ : masing-masing parameter Ln_KURS, INFLASI, SBI

$\Gamma_{\mathrm{ix}} \quad:$ koefisien hubungan jangka pendek

$\mathrm{e}_{\mathrm{t}} \quad$ : Error

$i \quad$ : panjang lag $(\mathrm{i}=1,2,3 \ldots)$ 
Untuk mendapatkan hasil estimasi VECM dilakukan melalui tahapan-tahapan uji pra-estimasi yaitu uji stasioneritas data, uji penentuan lag optimum dan uji kointegrasi (Firdaus 2011; Juanda dan Junaidi 2012). Apabila terdapat data yang stasioner pada level namun tidak memiliki kointegrasi maka tidak dapat dilakukan pendekatan melalui VECM, setelah mendapatkan hasil estimasi dari VECM maka dilakukan estimasi untuk menganalisis proyeksi dimasa yang akan datang dengan uji Impuls Respons Function (IRF) dan Forecast Error Variance Decomposition (FEDV) (Firdaus 2011; Juanda dan Junaidi 2012).

\section{HASIL DAN PEMBAHASAN}

\section{Hasil pengujian pra-estimasi}

Berdasarkan uji stasioneritas pada setiap model persamaan perusahaan agribisnis diperoleh bahwa model persamaan seluruh perusahaan agribisnis tidak stasioner pada tingkat level dan stasioner pada first difference (Lampiran 1). Selain itu, pada uji lag optimum menunjukkan bahwa masingmasing model persamaan perusahaan mendapatkan nilai lag yang berbeda berdasarkan kriteria AIC, SC dan HQ. Berdasarkan hasil uji stabilitas VAR, seluruh model persamaan perusahaan diperoleh nilai modulus kurang dari satu sehingga model masing-masing perusahaan dianggap stabil. berdasarkan hasil uji kointegrasi dengan menggunakan metode uji dari Johansen Trace Statistic. Kriteria pengujian kointegrasi pada penelitian ini didasarkan pada trace statistic. Hasil menunjukkan bahwa ada delapan model perusahaan yang terkointegrasi yaitu UNSP, SGRO, LSIP, TBLA, AALI, CPRO, CPIN, BISI dan satu model persamaan perusahaan yang tidak terkointegrasi yaitu MAIN. Berdasarkan hal tersebut, model persamaan perusahaan MAIN tidak diikutsertakan dalam mendapatkan hasil estimasi VECM, IRF dan FEDV.

\section{Hasil Estimasi model persamaan perusahaan}

Hasil estimasi VECM menunjukkan bahwa respons harga saham perusahaan agribisnis terhadap ketiga variabel makroekonomi berbeda-beda baik pada hubungan jangka pendek maupun hubungan jangka panjang (Lampiran 2 dan Lampiran 3). Suatu variabel bereaksi pada variabel lainnya membutuhkan waktu (lag) dan pada umumnya reaksi suatu variabel terhadap variabel lainnya terjadi pada jangka panjang.

Pertama, pada variabel nilai tukar, dalam hubungan jangka pendek variabel tersebut berpengaruh positif secara signifikan pada perusahaan BISI (Lampiran 2). Dalam hubungan jangka panjang variabel nilai tukar berpengaruh negatif secara signifikan pada perusahaan BISI, UNSP, SGRO, TBLA dan AALI dan berpengaruh positif pada perusahaan CPIN dan LSIP (Lampiran 3). Kondisi tersebut dapat diartikan bahwa pengaruh nilai tukar terhadap perusahaan berbeda karena perusahaan dengan besaran dan orientasi pasar yang berbeda akan merespon dampak perubahan nilai tukar yang juga berbeda. Perbedaan tersebut misalnya ketika kenaikan dollar US yang tajam terhadap rupiah akan berdampak negatif pada harga saham perusahaan yang memiliki utang yang besar dalam dollar sementara itu perusahaan yang berorientasi ekspor akan menerima dampak positif dari pelemahan nilai tukar. BISI sebagai perusahaan yang bergerak di bidang pangan yaitu perbenihan lebih banyak pada pasar domestik sehingga di jangka panjang berpengaruh secara negatif. Begitupun dengan perusahaan perkebunan yang mana komoditas utamanya kelapa sawit dengan orientasi ekspor, sehingga perubahan nilai tukar dapat memengaruhi nilai harga sahamnya. Nilai tukar berpengaruh pada harga saham juga sesuai dengan penelitian yang dilakukan oleh (Hadiansyah dan Gunawan 2017; Talla 2013 Yogaswari, et al 2012; Singh 2011) yang menyatakan nilai tukar berpengaruh negatif serta (Palatte dan Akbar 2014; Prio 2010;) yang menyatakan nilai tukar berpengaruh positif.

Kedua, pada variabel inflasi, dalam hubungan jangka pendek inflasi berpengaruh negatif pada UNSP, SGRO, AALI dan CPRO (Lampiran 2). Dalam hubungan jangka panjang, variabel inflasi berpengaruh positif secara signifikan hanya pada perusahaan TBLA dan seperti dalam jangka pendek variabel inflasi berpengaruh negatif secara signifikan pada perusahaan BISI, CPIN, UNSP, SGRO, AALI, CPRO (Lampiran 3). Pada umumnya, inflasi akan berpengaruh 
negatif pada harga saham perusahaan agribisnis baik pada komoditas utama perusahaan perkebunan yaitu kelapa sawit, pangan yaitu perbenihan, perikanan dan peternakan mengenai impor pakannya, mengingat karena dalam kondisi inflasi naik beban biaya produksi mengalami kenaikan yang mengakibatkan harga barang menjadi naik secara terus menerus selain itu kenaikan inflasi juga bisa disertai dengan nilai tukar yang melemah, sehingga perusahaan yang memiliki utang luar negeri harus membayar biaya bunga yang lebih tinggi yang berakibat pada penjualan yang akan turun dan penurunan laba perusahaan sehingga harga saham akan mengikuti penurunan. Kondisi tersebut juga sesuai dengan penelitian (Suselo 2015; Rakasetya, dkk 2013; Lawrence 2013; Efni 2013) yang menyatakan bahwa inflasi berpengaruh negatif terhadap harga saham perusahaan.

Ketiga, pada variabel Suku bunga BI, dalam hubungan jangka pendek variabel makroekonomi tersebut berpengaruh negatif secara signifikan hanya pada CPRO (Lampiran 2). Dalam hubungan jangka panjang, variabel Suku bunga BI berpengaruh positif secara signifikan pada perusahaan BISI dan TBLA serta berpengaruh negatif pada CPIN dan LSIP (Lampiran 3). Suku bunga BI merupakan pengendalian dalam menahan laju inflasi di mana ketika Suku bunga BI tinggi akan mendorong orang untuk menyimpan dananya di bank daripada melakukan investasi dalam bentuk deposito daripada melakukan perdagangan saham yang dapat menghasilkan risiko. Kondisi tersebut didukung penelitian oleh (Satria, dkk 2016; Pasaribu dan Firdaus 2013) yang menyatakan bahwa Suku bunga BI berpengaruh positif sedangkan (Prio 2010; Nurhidayat 2009) menyatakan bahwa Suku bunga BI berpengaruh negatif.

Berdasarkan penjelasan mengenai reaksi harga saham perusahaan agribisnis terhadap perubahan variabel makroekonomi maka dapat disimpulkan bahwa dalam menjalankan aktifitas perdagangan di bursa, pelaku perdagangan bursa harus memerhatikan dengan baik bagaimana perubahan dari ketiga variabel makroekonomi tersebut agar dapat mendapatkan hasil yang optimal.

\section{Analisis Impuls Response Function (IRF)}

IRF digunakan untuk mengetahui respons dari variabel ketika terjadi guncangan pada variabel yang lainnya. Dalam penelitian ini, jangka waktu yang digunakan untuk menganalisis respon harga saham terhadap variabel makroekonomi diproyeksikan dalam 48 bulan (4 tahun) ke depan. Secara umum, berdasarkan hasil IRF, respons harga saham terhadap guncangan atau perubahan variabel makroekonomi bervariasi pada masing-masing perusahaan agribisnis (Gambar 2)

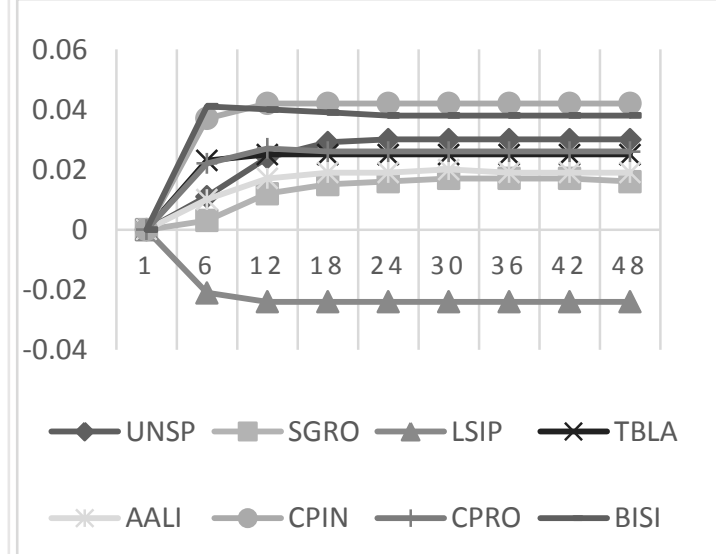

A. Reaksi harga saham terhadap perubahan nilai tukar

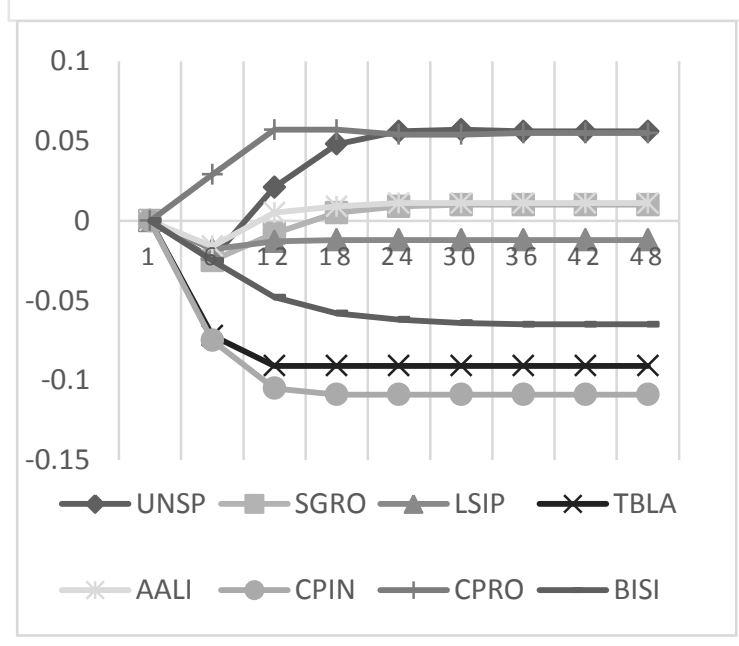

B. Reaksi harga saham terhadap perubahan inflasi 


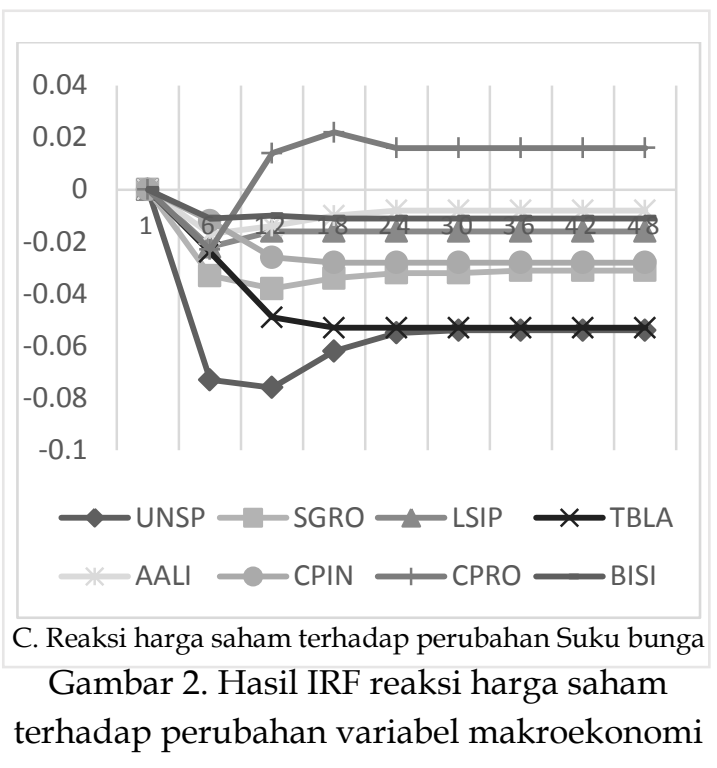

Pada bulan pertama perubahan nilai tukar, inflasi dan Suku bunga BI sebesar satu standar deviasi belum ada reaksi dari harga saham pada semua perusahaan dan baru bulan kedua respons dari harga saham mulai terlihat. Respons harga saham perusahaan terhadap ketiga variabel makroekonomi tersebut berbeda-beda. Pada variabel nilai tukar, hampir semua harga saham perusahaan merespons positif terhadap perubahan nilai tukar, kecuali perusahaan BISI yang merespons negatif (Gambar 2-A). seluruh perusahaan agribisnis menjual produknya di pasar ekspor sehingga dengan nilai tukar rupiah melemah maka dapat meingkatkan pendapatan perusahaan yang juga sekaligus menaikan nilai dari harga saham itu sendiri, namun berbeda dengan reaksi negatif harga saham perusahaan BISI dikarenakan pangsa dan jumlah ekspornya masih terbatas. Menurut Kementrian Pertanian, tahun 2018 eskpor jagung baru akan dimulai dari tetangga terdekat yaitu Malaysia dan Filipina. Pada variabel inflasi, saham perusahaan yang memberikan respons positif terhadap perubahan inflasi yaitu harga saham UNSP, SGRO, AALI, CPRO, sedangkan harga saham LSIP, TBLA, CPIN, BISI meresponsnya secara negatif (Gambar 2-B). Pada dasarnya inflasi merupakan faktor makroekonomi yang bisa merugikan konsumen karena terjadinya kenaikan dari harga barang-barang, namun bagi perusahaan kondisi tersebut di suatu waktu dapat memberikan efek positif yang disebabkan oleh kondisi kinerja perusahaan. UNSP, SGRO dan AALI merupakan perusahaan perkebunan yang tidak hanya fokus pada kelapa sawit tetapi terintegrasi dengan komoditas yang lain sehingga dapat melakukan efisiensi kegiatan usaha yang mana menurut Purwanti dkk (2014) penyebab inflasi bisa berasal dari dorongan biaya produksi terus menerus dalam jangka waktu tertentu. UNSP dengan komoditas karet, SGRO dengan komoditas karet dan sagu, AALI dengan usaha peternakan sapi. Kondisi tersebut dapat menenangkan kekhawatiran dari investor. Pada variabel Suku bunga BI, perubahan variabel tersebut menyebabkan hampir semua harga saham perusahaan merespons secara negatif kecuali harga saham perusahaan UNSP (Gambar 2C). Perubahan Suku bunga BI yang berpengaruh positif diduga karena tingkat perubahan Suku bunga BI yang sangat kecil sehingga tidak berdampak begitu besar pada perusahaan (Jayadin 2011). Secara keseluruhan, respons harga saham perusahaan terhadap perubahan nilai tukar, inflasi dan Suku bunga BI terjadi keseimbangan dalam kurun waktu kurang dari dua tahun. Hal tersebut diartikan bahwa harga saham perusahaan dapat dinyatakan stabil dalam waktu yang cepat ketika terjadi perubahan nilai tukar, inflasi dan suku bunga BI.

\section{Forecasting Error Variance Decompositon (FEDV)}

FEDV digunakan untuk melihat seberapa besar peranan perubahan variabel harga saham perusahaan agribisnis dan makroekonomi dalam menjelaskan pergerakan dan peramalan. Kondisi perubahan Suku bunga BI terjadi pada UNSP dan SGRO namun berbeda pada LSIP dan AALI yang dipengaruhi oleh nilai tukar dimana pada saat nilai rupiah mengalami pelemahan depresiasi maka hal tersebut menunjukan situasi fundamental perekonomian Indonesia sedang tidak baik, namun hal itu bisa membawa dampak positif pada perusahaan ketika perusahaan perkebunan menjual hasil produknya dengan segmentasi pasar ekspor. Hal tersebut juga sesuai dengan penelitian sebelumnya (Dirga 2016; Jayadin 2012; Prio 2010) yang menunjukkan bahwa nilai tukar berpengaruh positif terhadap perusahaan perkebunan, selain itu perusahaan perkebunan memiliki nilai investasi asing yang besar sehingga kondisi guncangan nilai tukar dan suku 
bunga BI yang diakibatkan oleh kondisi ekonomi global dapat berpengaruh pada kondisi harga saham perusahaan-perusahaan perkebunan. Nilai investasi asing subsektor perkebunan peringkat ke 7 (BKPM 2018).

Variabel makroekonomi yang berkontribusi terbesar pada perusahaan CPIN, CPRO dan BISI adalah inflasi, dimana kondisi tersebut memberikan gambaran tentang peningkatan harga-harga barang dan jasa yang diproduksi. CPIN sebagai perusahaan pakan ternak yang membutuhkan bahan baku seperti jagung, bungkil kacang kedelai dan bahan lainnya yang cenderung merupakan jenis dari produk mentah yang di impor sehingga kenaikan harga dapat menyebabkan kondisi yang tidak baik bagi perusahaan. Sama juga dengan CPRO yang bergerak pada subsektor perikanan yaitu pertambakan udang yang mana kebutuhan untuk pakan sangat besar, begitupun juga BISI yang bergerak dalam perbenihan pangan yang membutuhkan benih sayuran, buah-buahan dan bahan baku pestisida. Berdasarkan penjelasan, maka dapat disimpulkan bahwa terdapat persamaan di antara perusahaan CPIN, BISI dan CPRO yang mana variabel inflasi yang mendominasi, sementara itu pada perusahaan UNSP dan SGRO didominasi oleh kurs dan perusahaan LSIP dan AALI oleh perubahan Suku bunga BI. Hasil selengkapnya dapat dilihat pada Lampiran 4.

\section{KESIMPULAN DAN SARAN}

\section{KESIMPULAN}

Hasil penelitian menunjukkan bahwa reaksi harga saham perusahaan agribisnis pada indeks LQ-45 berbeda-beda terhadap perubahan variabel makroekonomi baik pada hubungan jangka pendek maupun hubungan jangka panjang. Pada jangka pendek, terdapat satu harga saham perusahaan yang signifikan bereaksi positif terhadap perubahan nilai tukar, pada perubahan inflasi didapatkan empat harga saham perusahaan yang secara signifikan berpengaruh negatif dan perubahan Suku bunga BI menyebabkan satu perusahaan signifikan berpengaruh negatif. Pada jangka panjang, didapatkan dua harga saham perusahaan bereaksi positif terhadap perubahan nilai tukar dan lima harga saham perusahaan yang secara signifikan bereaksi negative. Pada perubahan inflasi didapatkan satu perusahaan yang secara signifikan bereaksi positif dan enam harga saham perusahaan yang bereaksi negatif. Pada perubahan Suku bunga BI menyebabkan dua harga saham perusahaan yang secara signifikan bereaksi positif dan dua harga saham perusahaan yang bereaksi negatif. Hasil IRF menunjukan reaksi harga saham perusahaan terhadap perubahan nilai tukar, inflasi dan Suku bunga BI terjadi keseimbangan dalam kurun waktu kurang dari dua tahun. Sementara itu, hasil FEDV menghasilkan bahwa kontribusi variabel makroekonomi berbeda-beda pada masingmasing harga saham perusahaan.

\section{SARAN}

Bagi perusahaan agribisnis disarankan untuk melakukan dan menambah komoditas bisnis yang terintegrasi dengan komoditas pertanian yang lain agar dapat meningkatkan efisiensi usaha. Bagi investor, selain harus memerhatikan pergerakan perubahan variabel makroekonomi juga penting untuk melihat kontribusi terbesar dari variabel makroekonomi tersebut terhadap masingmasing perusahaan yang bergerak pada sektor agribisnis. Kemudian untuk Pemerintah disarankan untuk senantiasa mengelola iklim usaha dengan menjaga laju pertumbuhan ekonomi tetap baik, menjaga stabilitas inflasi dan suku bunga BI melalui kebijakan fiskal dan moneter agar tidak merugikan para pengusaha.

Penelitian selanjutnya disarankan untuk mengelompokkan dan membandingkan antar perusahaan agribinsis yang tercatat pada indeks yang lain selain indeks LQ-45, selain itu dapat membandingkan perusahaan agribisnis yang dimiliki oleh swasta dan negara agar dapat dilihat lebih mendalam bagaimana dampak dari perubahan variabel makroekonomi terhadap kinerja dari masingmasing kelompok jenis kepemilikan dari perusahaan tersebut. Disarankan juga untuk menambah variabel lain seperti kondisi pasar saham di negara lain, GDP negara, nilai dari perdagangan saham dan harga komoditas.

\section{DAFTAR PUSTAKA}

Abu FRA. 2011. Pengaruh harga minyak dunia dan variabel makroekonomi terhadap indeks harga saham (studi 
komparatif : Asia Tenggara, Asia Timus, Eropa dan Amerika). (Tesis). Bogor : Institut Pertanian Bogor.

Al-Majali AA and Al-Assaf GI. 2014.Long run and the short-run relationship between the stock market index and main macroeconomic variables performance in Jordan. European Scientific journal. 10(10): 156-171.

[BKPM] Badan Koordinasi Penanaman Modal (ID). 2018. Realisasi Penanaman Modal PMDN-PMA. Jakarta : Badan Koordinasi Penanaman Modal.

[BPS] Badan Pusat Statistik (ID). 2018. Laporan Perekonomian Indonesia tahun 2017. Jakarta: Badan Pusat Statistik.

Caporale MG and Soliman. 2013. Stock prices and Monetary policy an impulse response analysis. International Journal of Economics and Financial Issues. 3(3): 701-709.

Dirga SP, Siregar H, Sinaga BM. 2016.

$\begin{array}{lrr}\text { Analisis } & \text { pengaruh } & \text { variabel } \\ \text { makroekonomi } & \text { terhadap } & \text { return } \\ \text { kelompok } & \text { saham } & \text { subsektor } \\ \text { perkebunan. } & \text { Jurnal } & \text { Aplikasi } \\ \text { Manajemen. 14(3): } 595-607 . & \end{array}$

Efni Y.2013. Pengaruh suku bunga deposito, SBI, Kurs dan Inflasi terhadap Harga Saham Perusahaan Real Estate dan Porperty di BEI. Jurnal Ekonomi. 17(1) : 1-12.

Firdaus M. 2011. Aplikasi Ekonometrika Untuk Data Panel dan Time Series. Ed. ke-7. Bogor: IPB Press.

Global Entrepreneurship Index. 2018. The Global Entrepreneurship Index. Washington, D.C (US).

Hadiansyah N, Gunawan BH. 2017. Analisis Makroekonomi dan Fundamental Terhadap Harga Saham Perbankan Yang Terdaftar Pada Indeks LQ 45. Jurnal Ekonomi Bisnis. Vol 22 : 26-36.

[IDX] Bursa Efek Indonesia (ID). 2010. Buku panduan Indeks Harga Saham Bursa Efek Indonesia. Jakarta: Indonesia Stock Exchange.

Jayadin. 2011. Analisis Pengaruh

Makroekonomi, IHSG dan Harga Minyak Dunia Terhadap Return Saham-Saham Energi dan Pertambangan Energi. [Tesis]. Bogor: Institut Pertanian Bogor.

Juanda B, Junaidi. 2012. Ekonometrika Deret Waktu. Ed. Ke-1. Bogor: IPB Press.

Lawrence SS. 2013. Pengaruh variabel makroekonomi dan harga komoditas terhadap indeks harga saham gabungan di Indonesia. Jurnal Finesta. 1(2): 18-23.

Maysami RC, Kho TS (2000). A vector error correction model of the Singapore stock market. International Review of Economics and Finance. 9(1): 79-96.

Kuwornu JKM. 2011. Macroeconomic variables and stock market full information maximum likelihood estimation. Research Journal of Finance and Accounting. 2(4): 49-63.

Nurhidayat R. 2009. Pengaruh Variabel Ekonomi Makro Terhadap Return Saham Properti pada Bursa Efek Indonesia. Kajian Ekonomi dan Keuangan. Departemen Keuangan Republik Indonesia. 13(2) : 1-13.

[OJK] Otoritas Jasa Keuangan (ID). 2017. Highlight sektor Subbagian Agrobisnis. Jakarta: Otoritas Jasa Keuangan.

Pasaribu RBF, Firdaus M. 2013. Analisis pengaruh variabel makroekonomi terhadap indeks saham syariah Indonesia. Journal Ekonomi dan Bisnis. 7(2): 117-128.

Palatte dan Akbar. 2014. Pengaruh nilai tukar mata uang dan tingkat Suku bunga BI terhadap perkembangan indeks harga saham gabungan di bursa efek Indonesia periode 2009-2013. Jurnal Manajemen. 1(2): 39-57. 
Polakitan DC. 2015. Analisis komparasi risiko saham LQ 45 dan non LQ 45 pada beberapa sub sektor perusahaan yang terdaftar di Bursa Efek Indonesia. Jurnal Riset Bisnis dan Manajemen. 3(1): 61-72.

Prakoso DN, Firdaus M dan Andati T. 2018. Pengaruh variabel makroekonomi terhadap return indeks LQ-45 dan Pefindo 25. Jurnal Aplikasi Manajemen dan Bisnis. 4(3): 387 - 397.

Prio SD. 2010. Pengaruh pasar saham dunia dan variabel makroekonomi terhadap IHSG dan LQ45 [tesis]. Bogor (ID): Institut Pertanian Bogor.

Purwanti ES, Arsinta Y, Arisanti NFD dan Azizah IN. 2014. Dampak impor terhadap inflasi Indonesia triwulan 1 tahun 2014. Economics Development Analysis Journal. 3(2): 381-392.

Rakasetya GG, Darminto dan Dzulkirom. 2013. Pengaruh faktor mikro dan faktor makro ekonomi terhadap harga saham perusahaan mining and mining services yang terdaftar di bursa efek Indonesia (BEI) periode 2008-2011. Jurnal Administrasi Bisnis. 6(2) : 1-12.

Satria, Made WA dan Sudjarni LK. 2016. Pengaruh tingkat Suku bunga BI, tingkat inflasi, nilai kurs rupiah dan produk domestic bruto terhadap return saham. Jurnal Manajemen Unud. 5(6) : 3392-3240.

Sensus Pertanian. 2014. Analisis Rumah

Tangga, Lahan, dan Usaha Pertanian di Indonesia : sensus pertanian 2013. Direktorat Pangan dan Pertanian. Kementrian Perencanaan Pembangunan Nasional.

Singh T. Mehta S. and Varsha MS. 2011.

Macroeconomic factors and stock return: evidence from Taiwan. Journal of Economics and International Finance. 2(4) : 217-227.

Suselo D. 2015. Pengaruh Variabel Fundamental dan Makro Ekonomi terhadap Harga Saham (Studi pada Perusahaan yang masuk dalam indeks
LQ45). Jurnal Aplikasi Manajemen. 13(1) : $104-116$.

Suyati S. 2015. Pengaruh inflasi, tingkat suku bunga dan nilai tukar rupiah/us dollar terhadap return saham property yang terdaftar di bursa efek Indonesia. Jurnal Ilmiah UNTAG Semarang. 4(3) : $70-86$.

Talla JT. 2013. Impact of Macroeconomic Variables on the stock Market Prices of the Stockholm Stock Exchange. [thesis]. Master`s thesis in International Financial Analysis. Jonkoping International Business School.

Yogaswari DD, Nugroho AD dan Astuti NC. 2012. The Effect of Macroeconomic Variables on Stock Price Volatility Evidence from Jakarta Composite Index, Agriculture, and Basic Industry Sector. Journal of Business and Management. 46: 96-100. 
Lampiran 1. Hasil Uji stasioneritas

\begin{tabular}{|l|l|l|l|l|l|l|}
\hline \multicolumn{1}{|c|}{ Variabel } & \multicolumn{3}{|c}{ Level } & \multicolumn{3}{c|}{ First Difference } \\
& t-ADF & $\begin{array}{l}\text { MacKinnon } \\
\mathbf{( 5 \% )}\end{array}$ & Prob* & t-ADF & $\begin{array}{l}\text { MacKinnon } \\
\mathbf{( 5 \% )}\end{array}$ & Prob* $^{*}$ \\
\hline LN_BISI & $-0,631366$ & $-2,883579$ & 0,8586 & $-10,15768$ & $-2,883753$ & $\mathbf{0 , 0 0 0 0}$ \\
\hline LN_CPIN & $-1,281197$ & $-2,883579$ & 0,6371 & $-10,63438$ & $-2,883753$ & $\mathbf{0 , 0 0 0 0}$ \\
\hline LN_MAIN & $-1,566887$ & $-2,883579$ & 0,4966 & $-11,54187$ & $-2,883753$ & $\mathbf{0 , 0 0 0 0}$ \\
\hline LN_CPRO & $-6,387123$ & $-2,884665$ & $\mathbf{0 , 0 0 0 0}$ & $-6,330416$ & $-2,884665$ & $\mathbf{0 , 0 0 0 0}$ \\
\hline LN_UNSP & $-1,358265$ & $-2,883753$ & 0,6008 & $-8,593562$ & $-2,883753$ & $\mathbf{0 , 0 0 0 0}$ \\
\hline LN_SGRO & $-3,185394$ & $-2,883753$ & 0,0231 & $-7,949856$ & $-2,883753$ & $\mathbf{0 , 0 0 0 0}$ \\
\hline LN_LSIP & $-2,598663$ & $-2,883579$ & 0,0958 & $-11,34572$ & $-2,883753$ & $\mathbf{0 , 0 0 0 0}$ \\
\hline LN_TBLA & $-1,535979$ & $-2,883579$ & 0,5124 & $-10,18722$ & $-2,883753$ & $\mathbf{0 , 0 0 0 0}$ \\
\hline LN_AALI & $-2,937543$ & $-2,883579$ & 0,0438 & $-11,41391$ & $-2,883753$ & $\mathbf{0 , 0 0 0 0}$ \\
\hline INF & $-2,510984$ & $-2,883753$ & 0,1152 & $-7,441987$ & $-2,883753$ & $\mathbf{0 , 0 0 0 0}$ \\
\hline SBI & $-2,220467$ & $-2,883930$ & 0,2001 & $-4,597687$ & $-2,883930$ & $\mathbf{0 , 0 0 0 2}$ \\
\hline LN_KURS & $-0,631366$ & $-2,883579$ & 0,8586 & $-10,43042$ & $-2,883753$ & $\mathbf{0 , 0 0 0 0}$ \\
\hline
\end{tabular}

Lampiran 2. Hasil estimasi VECM Jangka Pendek

\begin{tabular}{|c|c|c|c|c|c|c|c|c|}
\hline \multirow[b]{2}{*}{$\begin{array}{l}\text { Variabel } \\
\text { Lag }\end{array}$} & \multicolumn{8}{|c|}{ Koefisien } \\
\hline & $\begin{array}{l}\text { UNSP } \\
(-2)\end{array}$ & $\begin{array}{l}\text { SGRO } \\
(-2)\end{array}$ & $\begin{array}{l}\text { LSIP } \\
(-1)\end{array}$ & $\begin{array}{l}\text { TBLA } \\
(-3)\end{array}$ & $\begin{array}{l}\text { AALI } \\
(-2)\end{array}$ & $\begin{array}{l}\text { CPIN } \\
(-1)\end{array}$ & $\begin{array}{l}\text { CPRO } \\
(-2)\end{array}$ & $\begin{array}{l}\text { BISI } \\
(-2)\end{array}$ \\
\hline cointEq1 & $-0,006$ & $-0,002$ & $-0,050$ & $-0,117^{\text {** }}$ & 0,001 & $0,054^{* *}$ & $-0,102^{* *}$ & $0,015^{\text {** }}$ \\
\hline D(LN_HARGA) & $-0,013$ & $-0,110$ & 0,025 & 0,117 & $-0,078$ & $-0,107$ & 0,142 & $-0,034$ \\
\hline $\begin{array}{l}\text { D(LN_NILAI } \\
\text { TUKAR) }\end{array}$ & 0,234 & $-0,036$ & 0,273 & 0,156 & 0,607 & 0,042 & 0,316 & $0,957^{* *}$ \\
\hline $\mathrm{D}(\mathrm{INF})$ & $-0,044^{* *}$ & $-0,030 * *$ & $-0,015$ & $-0,017$ & $-0,036^{* *}$ & $-0,007$ & $-0,038^{* *}$ & 0,010 \\
\hline $\mathrm{D}(\mathrm{SBI})$ & $-0,109$ & 0,002 & $-0,110$ & $-0,071$ & $-0,011$ & 0,045 & $-0,101^{* *}$ & 0,004 \\
\hline $\mathrm{C}$ & - & - & $-0,005$ & - & - & 0,032 & - & - \\
\hline
\end{tabular}

Lampiran 3. Hasil estimasi VECM Jangka Panjang

\begin{tabular}{|c|c|c|c|c|c|c|c|c|}
\hline \multirow{2}{*}{ Variabel } & \multicolumn{8}{|c|}{ Koefisien } \\
\hline & UNSP & SGRO & LSIP & TBLA & AALI & CPIN & CPRO & BISI \\
\hline cointEq1 & 1,000 & 1,000 & 1,000 & 1,000 & 1,000 & 1,000 & 1,000 & 1,000 \\
\hline LN_NILAI TUKAR (-1) & $-0,469 * *$ & $-0,862^{* *}$ & $4,410^{* *}$ & $-0,859 * *$ & $-0,965^{* *}$ & $13,203^{* *}$ & $-0,512$ & $-1,026^{* *}$ \\
\hline $\operatorname{INF}(-1)$ & $-1,187^{* *}$ & $-0,322$ ** & $-0,038$ & $0,092 * *$ & $-0,247^{* *}$ & $-0,438^{* *}$ & $-0,103^{* *}$ & $-1,153^{* *}$ \\
\hline SBI $(-1)$ & 0,495 & 0,279 & $-0,181^{* *}$ & $0,195^{\star *}$ & 0,046 & $-0,446^{* *}$ & $-0,069$ & $1,224^{* *}$ \\
\hline
\end{tabular}




\section{Lampiran 4. Hasil FEDV}

\begin{tabular}{|c|c|c|c|c|c|c|c|c|c|}
\hline \multirow{2}{*}{ Variabel } & \multirow{2}{*}{ Periode } & \multicolumn{8}{|c|}{ Perusahaan } \\
\hline & & UNSP & SGRO & LSIP & TBLA & AALI & CPRO & CPIN & BISI \\
\hline \multirow{5}{*}{$\begin{array}{c}\text { Harga } \\
(\%)\end{array}$} & 1 & 100 & 100 & 100 & 100 & 100 & 100 & 100 & 100 \\
\hline & 12 & 80,26 & 89,91 & 94,54 & 58,81 & 95,27 & 86,22 & 80,26 & 88,6 \\
\hline & 24 & 75,28 & 87,99 & 94,03 & 42,39 & 94,42 & 57,88 & 75,28 & 85,83 \\
\hline & 36 & 73,92 & 87,02 & 93,85 & 37,07 & 93,81 & 46,74 & 73,92 & 84,5 \\
\hline & 48 & 73,3 & 86,49 & 93,75 & 34,43 & 93,48 & 38,87 & 73,3 & 83,7 \\
\hline \multirow{5}{*}{$\begin{array}{c}\text { Nilai } \\
\text { tukar }(\%)\end{array}$} & 1 & 0 & 0 & 0 & 0 & 0 & 0 & 0 & 0 \\
\hline & 12 & 3,34 & 0,41 & 2,15 & 3,7 & 1,52 & 3,57 & 3,34 & 7,08 \\
\hline & 24 & 3,47 & 1,22 & 2,94 & 3,88 & 2,69 & 2,7 & 3,47 & 5,92 \\
\hline & 36 & 3,49 & 1,75 & 3,23 & 3,94 & 3,34 & 2,16 & 3,49 & 5,42 \\
\hline & 48 & 3,5 & 2,05 & 3,38 & 3,97 & 3,71 & 1,78 & 3,5 & 5,16 \\
\hline \multirow{5}{*}{$\begin{array}{c}\text { Inflasi } \\
(\%)\end{array}$} & 1 & 0 & 0 & 0 & 0 & 0 & 0 & 0 & 0 \\
\hline & 12 & 15,79 & 3,11 & 1,31 & 31,11 & 1,4 & 5,39 & 15,79 & 3,71 \\
\hline & 24 & 20,05 & 2,01 & 1,17 & 41,77 & 1,25 & 13,34 & 20,05 & 7,72 \\
\hline & 36 & 21,25 & 1,77 & 1,11 & 45,15 & 1,4 & 12,59 & 21,25 & 9,62 \\
\hline & 48 & 21,79 & 1,63 & 1,08 & 46,82 & 1,47 & 12,44 & 21,79 & 10,6 \\
\hline \multirow{5}{*}{$\begin{array}{c}\text { Suku } \\
\text { bunga BI } \\
(\%)\end{array}$} & 1 & 0 & 0 & 0 & 0 & 0 & 0 & 0 & 0 \\
\hline & 12 & 0,71 & 6,57 & 2 & 6,38 & 1,81 & 4,81 & 0,71 & 0,61 \\
\hline & 24 & 1,2 & 8,78 & 1,86 & 11,96 & 1,64 & 26,07 & 1,2 & 0,51 \\
\hline & 36 & 1,34 & 9,46 & 1,81 & 13,84 & 1,45 & 38,51 & 1,34 & 0,48 \\
\hline & 48 & 1,41 & 9,83 & 1,78 & 14,76 & 1,34 & 46,91 & 1,41 & 0,47 \\
\hline
\end{tabular}

